\title{
O RATO DE CLARICE - cartografias de linguagem
}

\author{
El RATÓN DE LA CLARICE - cartografias de lenguaje \\ THE CLARICE'S RAT - language's cartography
}

\author{
Ana Carolina de Oliveira Marques \\ Universidade Estadual de Goiás \\ carol.geografia@hotmail.com \\ Eguimar Felício Chaveiro \\ Universidade Federal de Goiás \\ eguimar@hotmail.com
}

\begin{abstract}
Resumo: De "Perdoando Deus", conto anexado à coletânea "Felicidade Clandestina", partiram as consideraçôes elencadas neste artigo. Propondo uma cartografia das emoçóes ali enunciadas, buscou-se revelar, junto a fragmentos da trajetória de vida da escritora Clarice Lispector, o tempo social e o espaço nos quais aterrissam as sensações de paz, revolta, medo, tristeza, aceitação exprimidas no texto. Na centralidade da análise, situouse a metáfora do rato morto no calçadão de Copacabana, no Rio de Janeiro. Tal conto traduz demandas existenciais que ultrapassam a individualidade da escritora, estendendo-se aos sujeitos e à produçáo do espaço urbano na contemporaneidade. "Perdoando Deus" é, acima de tudo, um chamado à vida intensa, frente a uma existência que abarca também o desorganizado, o inacabado, o devir.
\end{abstract}

Palavras-chave: Clarice Lispector, Leitura, Escrita, Engajamento.

Resumen: De "Perdonando Dios", cuento anexo a la collectanea "Felicidad Clandestina”, surgieron las consideraciones catalogadas en este articulo. Proponiendo una cartografía de las emociones allí anunciadas, se busca revelar, junto a fragmentos de trayectoria de vida de la escritora Clarice Lispector, el tiempo social y el espacio social en los cuales aterrizan las sensaciones de paz, revuelta, miedo, tristeza, aceptación exprimidos en el texto. En la centralidad del análisis, se sitúa la metáfora del ratón muerto en la vereda de Copacabana, en Rio de Janeiro. Tal cuento traduce demandas existenciales que ultrapasan la individualidad de la escritora, extendiéndose a los sujetos e a la producción del espacio urbano en la contemporaneidad. "Perdonando Dios" es, ante todo, um llamado a la vida intensa, frente a una existencia que abarca también lo desorganizado, lo inacabado, el devenir.

Palabras claves: Clarice Lispector, Lectura, Escritura, Compromiso. 
Abstract: Of "Forgiving God" story attached to the compilation " Clandestine Happiness," left the considerations listed in this article. Proposing a map of emotions set out there, we attempted to reveal, along with fragments of the life story of the writer Clarice Lispector, social time and space in which they land the feelings of peace, anger, fear, sadness, expressed accordingly in the text. The centrality of the analysis stood a mouse metaphor dead on the boardwalk of Copacabana, in Rio de Janeiro. This tale translates existential demands that go beyond the individuality of the writer, extending to the subjects and the production of urban space in contemporary times. "Forgiving God" is, above all, a call to intense life, against an existence that also embraces the disorganized, the unfinished, the becoming.

Keywords: Clarice Lispector, Reading, Writing, Engagement.

\section{INTRODUÇÃO}

A vida e obra de Clarice Lispector inquietam leitores, escritores, críticos literários, biógrafos. Sua escrita "simples", conforme declarara a escritora em sua última entrevista concedida à TV Cultura em 1977, veiculara cartografias singulares que colocam em suspensão o cotidiano, o espaço banal e os mistérios da mente humana.

Nas poucas entrevistas que concedera, Clarice admitiu sua relação visceral com a escrita: para ela, escrever preenchia uma espécie de vazio existencial que a assolava. Vazio que, ao mesmo tempo, era condição do exercício de liberdade que caracteriza seus textos. Aliás, pode-se dizer que a busca incessante por "liberdade" fora a condição fundamental do investimento de Clarice na escrita. $\mathrm{O}$ que não exime seus textos de conteúdos existenciais e políticos que ultrapassam a individualidade da escritora, contemplando importantes dilemas da sociedade e do sujeito contemporâneos.

De "Perdoando Deus", conto anexado à coletânea "Felicidade Clandestina", partiram as consideraçôes elencadas neste artigo. Propondo uma cartografia das emoções ali enunciadas, buscou-se revelar, junto a fragmentos da trajetória de vida da escritora Clarice Lispector, o tempo social e o espaço nos quais aterrissam as sensaçóes de paz, revolta, medo, tristeza, conformidade exprimidas no texto. $\mathrm{Na}$ centralidade da análise, situou-se a metáfora do rato morto no calçadão de Copacabana, no Rio de Janeiro.

A proposta do artigo não fora utilizar o conto expressão da realidade concreta, a partir do qual poder-se-ia compor novas ferramentas analíticas ou recursos didáticos para o estudo dos fenômenos sociais. Ao menos, náo só isso. Mais que documento, a arte pode ter - dada a multiplicidade de concepçóes do termo - um caráter performativo que coloca em suspensão conceitos, valores, morais dadas. Entende-se a arte, pois, enquanto inscrição de sujeitos, pensamentos, ações e lugares. Logo, não só o mundo tal como ele é, mas mundos possíveis ecoam nas composiçóes de Clarice.

O lugar de falas dos autores é, entretanto, a Geografia. A aproximação entre literatura e geografia marca esta ciência desde sua institucionalização. Há muito a literatura potencializa o olhar atento dos geógrafos às minúcias das paisagens - exercício essencial na compreensão da "geograficidade" dos fenômenos. Todavia, conceber a literatura como uma mera ferramenta de representação da realidade parece-nos equivocado. 
Tradicionalmente os geógrafos buscaram na literatura as particularidades dos lugares, as culturas locais e regionais. Há também, como é o caso daqueles que se aproximam da obra de Clarice Lispector, o interesse em desvendar alguns mistérios da mente e da emoçáo humanas. Daí a literatura como entrada ao estudo do sujeito.

Em tempos de evidente fracasso da linguagem burocrática da academia, e de uma geografia dos "grandes temas e espaços" na busca por respostas a problemas latentes de um mundo dilacerado, em adoecimento, onde questôes ontológicas emergem a todo momento, a literatura capta processos táo sutis da existência humana que enunciam elementos ainda intangíveis na produção do conhecimento científico.

Os fundamentos teóricos do presente artigo remetem à bibliografia discutida na disciplina "Tópicos em Análise do Discurso: Sujeito, Leitura e Escrita", ministrada pelo Prof. Dr. Agostinho Apotenciano, no âmbito de Programa de Pós-Graduação em Educação da Faculdade de Letras, da Universidade Federal de Goiás. Também as discussóes no Grupo de Pesquisa "Espaço, Sujeito e Existência", coordenado pelo professor Eguimar Felício Chaveiro. Esta última versão conta ainda com as reflexôes suscitadas no contexto do III Simpósio Internacional de Geografia, Literatura e Arte (SIGEOLITERART) - Dourados/ MS, 2017.

\section{GEOGRAFIA E LITERATURA}

A teoria dos campos, do sociólogo Pierre Bourdieu, veicula: há "segmentos" da vida social que operam com certa autonomia, detendo normas, capital, princípios, linguagem, habitus específicos. Seria o caso, dentre outros, do campo literário, científico, religioso, político. O que move o funcionamento de um campo é o trânsito de capitais (material e simbólico) entre os seus componentes, cujas posiçōes são variáveis, assim como as normas que os regem e os objetos que, estrategicamente, consagram.

A autonomia dos campos não impede a intersecção entre eles. Por isso, a envergadura deste texto: a interface entre a ciência e a arte, ou entre a Geografia e a Literatura, e o que isso implica em termos de leitura e escrita.

A interface Geografia e Literatura não é algo novo, a exemplo da obra do "clássico" Vidal La Blache, na qual a descrição dos gêneros de vida por vezes se ancora em narrativas literárias.

Nos dias atuais, um grupo de geógrafos humanistas - cuja rede de pesquisa se consolida ao poucos, sendo o SIGEOLIRART um dos espaços de diálogo entre esses pesquisadores - reclama a literatura como chave de um movimento de expansão das fronteiras da Geografia, ciência por séculos refém de um objeto de estudo - espaço - mensurado por medidas obsoletas num mundo de relações globalizadas/fluidas: tamanho, distância (métrica) e extensão.

É como base na leitura de texto de alguns desses geógrafos, participação em eventos específicos, grupos de estudo, arrisca-se apontar alguns desafios - e possíveis equívocos que acometem os geógrafos na aproximação com a literatura: 
1. A literatura como recurso didático no ensino de Geografia, e o risco de reduzi-la a documento comprobatório de um conteúdo/teoria já trabalhado em sala de aula - o mesmo ocorre com o cinema, a fotografia, a cartografia;

2. A literatura como "ornamentação" ou "oxigenação" do texto (o Eguimar diz algo mais ou menos assim), dissimulando uma fragilidade em termos de conteúdo;

3. A literatura como "produto cultural", endossando uma concepção de cultura deslocada das condiçóes materiais da existência, despindo, portanto, a literatura de sentido político. Nesta, enquadra-se a literatura de autoajuda.

As três vertentes aniquilam aquilo que faz da literatura, arte: a potência criadora. Potência instalada no mistério da diversidade dos modos pelos quais os sujeitos veem e são afetados pelo mundo. Esse mistério faz também da arte uma forte aliada da Geografia, uma ciência que, segundo Ruy Moreira (2011), tem como ponto de partida a percepção dos fenômenos, logo, os sentidos e sensaçóes humanas como matéria prima:

Nossa percepçáo sensível nos póe em contato com coisas singulares. Aos poucos, a observação atenta vai vendo nelas aspectos comuns e por meio da reuniáo desses aspectos vencemos o horizonte do singular e as transpomos para o universal. Surge, assim, um plano geral que nos permite voltar às coisas singulares para reunir agora para cada uma delas os aspectos que lhe são específicos e comuns, surgindo o horizonte da particularidade.

A representação é o mundo construído na dialética da imagem e da fala. Vimos que a imagem surge no campo da senso-percepçáo, e a fala surge no campo da tradução intelectiva dessas imagens.

A paisagem é o ponto de partida e o ponto de chegada na produção da representação em geografia. Isso significa valorizar a imagem e a fala na representação geográfica. E, assim, a sensibilidade e a intelecção. Daí que a geografia sempre pareça ficar num meio-termo entre a arte e a ciência, duas formas próprias de representação.

Não basta à Geografia, constituir a imagem e exprimi-la pela fala como sucede acontecer para a maioria das ciências. Mas descrevê-la em palavras com um rigor fotográfico. (MOREIRA, 2011 p. 107; p. 109).

Está aí a grandeza do texto geográfico: os detalhes, a paciência narrativa que retira da matéria cotidiana o conteúdo do mundo.

O geógrafo é constantemente desafiado a definir uma perspectiva (uma posição no campo visual) que lhe permita encontrar as pistas, no visível, do invisível que opera a passagem do singular ao universal.

O geógrafo lida primeiro e fundamentalmente com os sentidos e sensaçóes humanas, acionadas na ARTE DE OBSERVAR. Conforme revela o professor Ruy Moreira (2011), formar-se um bom observador e um minucioso narrador é a condição para todo o resto do trabalho a ser realizado. 


\section{SUJEITO, LEITURA, ESCRITA E ENGAJAMENTO}

A fim de evidenciar a relação sujeito-mundo-linguagem, inicia-se pelas implicaçóes da leitura e da escrita na formação do sujeito.

Duvidando a neutralidade desses processos - leitura, escrita e formação do sujeito -, ou seja, partindo da indissociabilidade entre o sujeito (leitor, escritor, autor, tradutor etc.), a ação e o objeto textual, alega-se: o texto sofre mutações conforme o contexto espaço-temporal, os sujeitos e as práticas empreendidas (CHARTIER, 1990). Logo, são múltiplas as possibilidades de escrita, de leitura, de interpretação textual. Também os são, os processos de introspecção provocados por essas práticas: não se tem o domínio das cartografias mentais que emergem de um texto literário.

Clarice Lispector fora prova do mistério que distancia e aproxima os sujeitos de suas práticas de leitura e escrita. Revelou a Lerner (1977), em entrevista publicada após sua morte - a pedido da própria Clarice - que, quando publicado, fugiu-lhe totalmente o

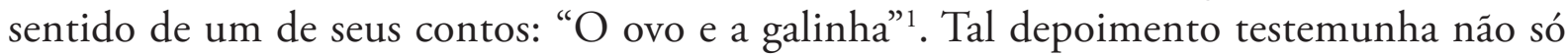
a "vida própria" tomada pelo texto finalizado, mas a potência do encontro leitor-obra, também enfatizada por Orlandi:

Quando lemos estamos produzindo sentidos (reproduzindo-os ou transformandoos). Mais do que isso, quando estamos lendo, estamos participando do processo (sócio-histórico) de produção de sentidos e o fazemos de um lugar social e com uma direção histórica determinada. (2006, p. 101).

O texto foge ao autor não só no campo das ideias, mas do vocabulário (exemplo da tradução), da edição, dos espaços de leitura, dos formatos dos livros, dos interlocutores, dos modos de ler. Ler em voz alta, em silêncio, no quarto, no metrô, sozinho, em coletivo, quando criança ou idoso, por meio de livros ou em ambiente virtual: há tantas leituras quanto leitores e formas de ler (MANGUEL, 1997). Daí o potencial criativo do leitor, que por meio de uma composição singular de suas leituras agencia os ditos e os não ditos: engaja-se no mundo.

A ideia de engajamento compartilhada neste artigo ultrapassa o sentido implícito em expressóes como "literatura engajada", que em geral remete ao tratamento de temas sociais por meio da literatura. Partilhando da proposição sartreana, o engajamento é aqui entendido como uma condição de sujeito responsável por suas ações (CHAVEIRO, s/d). Logo, ler vai além de inteirar-se dos conflitos individuais e coletivos, internos e externos envolvidos na existência: ler é, além de posicionar-se, compor-se.

Parafraseando Chaveiro (s/d), uma vez que "palavra é ação, e ler é desossar palavras", a leitura nada menos é que encontrar o outro, dar-lhe passagem, relacionar-se, construir mundos. Do mesmo modo, a escrita.

Para Orlandi (2006), não se separa o sujeito leitor/escritor da formação social. No intermédio, mas náo limitados a eles, estão os sentidos produzidos no ato de enunciação.

Anexado à coletânea "Felicidade Clandestina" (1998). 
Sentidos estes que têm historicidade, portanto dizem de um passado e de um futuro:

Esse projeto significante, se assim podemos denominar, ao mesmo tempo que "desgruda" o sujeito do imediatismo de uma relação mecânica com a situação de enunciação, o "prende" na responsabilidade [engajamento] do dizer, o de ser autor (leitor) e, logo, o de ser a origem, náo do discurso, mas de sua unidade e coerência. (2006, p. 103).

No caso de Clarice, escrever era a forma por excelência de dar vazão às experiências, recontá-las, refazê-las, agir sobre elas - ainda que o compromisso primeiro de sua escrita fora acertar contas com o interior de si:

Clarice Lispector (1977) - Eu não sou uma profissional, eu só escrevo quando eu quero. Eu sou uma amadora e faço questão de continuar sendo amadora. Profissional é aquele que tem uma obrigação consigo mesmo de escrever. Ou então com o outro, em relação ao outro. Agora eu faço questão de não ser uma profissional para manter minha liberdade. ${ }^{2}$

Manter a liberdade não implica ausentar-se dos problemas do mundo. Pelo contrário: grande parte dos escritos de Clarice tangencia a face perversa da sociedade capitalista, exemplo da sua última novela, intitulada "Treze nomes, treze títulos".

Entre as contradiçóes sociais e a natureza insolúvel do desejo, eis o diferencial da escritora: Clarice rompe a membrana que simula a dicotomia sujeito-mundo. Em seus textos, não há problema sem Clarice, ela está em todas as situaçôes que descreve: "Quando me comunico com o adulto, na verdade, estou me comunicando com o mais secreto de mim mesma" (LISPECTOR, 1977).

Seus escritos em geral acusam um estado de extrema angústia. Seria esta, como diria Orlandi (2006), a circunstância da enunciação de Clarice?

Fato é que os autodenominados "leitores de Clarice" reiteram a fusão total entre a vida e a obra da escritora:

Falar de João Guimarães Rosa é falar de "Grande Sertão: Veredas". Falar de Machado de Assis é, da mesma forma, falar de seus livros, e, só depois, do homem notável por trás deles. Mas falar de Clarice Lispector é falar de Clarice, o prenome pelo qual ela é universalmente conhecida: da mulher em si. De seu primeiro conto, publicado aos 19 anos, ao último, encontrado em fragmentos dispersos depois de sua morte, acompanhamos uma vida de experimentação artística por uma vasta gama de estilos e experiências. (CRUVINEL, 2015 p. 1).

O labirinto de sensaçóes que sustenta a obra de CL obriga o leitor a recolocar-se frente às contradiçóes do mundo e do próprio desejo. E mais: instiga-o a se reconhecer parte inseparável desse mundo em conflito.

"Perdoando Deus" tem um pouco de tudo isso: susto com o mundo tal como ele é e acalento com o sinal vital representado pelo próprio susto. À escritora, evasão de

$\overline{2}$ Entrevista concedida em 1977 ao repórter Júlio Lerner, na TV Cultura. 
incertezas quanto a si e ao mundo. Ao leitor, o convite à profundidade de um pensamento obcecado pela liberdade.

\section{O RATO DE CLARICE}

O enredo se passa no calçadão de Copacabana, na cidade do Rio de Janeiro. A personagem narradora faz do passeio um exercício de liberdade. A observação da paisagem urbana - edifícios, nesgas de mar - acusa um olhar desarmado, distraído.

A princípio, distração, depois contemplação e, por fim, afetação. A tomada de consciência da personagem acerca das sensaçóes que lhe acometia, acontecia à medida que tecia conexóes entre o que observava e os significados daquilo em seu mundo vivido. Mais que isso: aos poucos, a transeunte se sentia parte da paisagem:

Tive então um sentimento de que nunca ouvi falar. Por puro carinho, eu me senti a mãe de Deus, que era a Terra, o mundo. Por puro carinho, mesmo, sem nenhuma prepotência ou glória, sem o menor senso de superioridade ou igualdade, eu era por carinho a mãe do que existe. Soube também que se tudo isso "fosse mesmo" o que eu sentia - e não possivelmente um equívoco de sentimento - que Deus sem nenhum orgulho e nenhuma pequenez se deixaria acarinhar, e sem nenhum compromisso comigo. Ser-lhe-ia aceitável a intimidade com que eu fazia carinho (LISPECTOR, 1998, p. 41).

A sensação de que tudo lhe pertencia nada a tinha a ver com a noção de propriedade. O "amor livre", como fora declarado em trecho seguinte, contrapunha-se ao medo e à reverência que, em geral, pautam a relação das pessoas com espaços privativos. Pelo contrário: a ingenuidade da personagem repelia a ordem social que estratifica os sujeitos e lugares.

O embate entre o desejo de liberdade, o amor livre e as contradiçôes sociais marcam o ápice do enredo. Em meio ao existencialismo tornado "modo de caminhar", que fazia da transeunte a responsável pelo mundo que habita, o susto: um rato morto no calçadão.

O rato entra em cena para lembrar a personagem da conexão, em matéria de vida, entre o belo e o sangrento. A primeira contradição: a paisagem festiva que Copacabana oferece aos turistas e as vísceras expostas do rato morto. $\mathrm{O}$ medo se instaura:

Em menos de um segundo estava eu eriçada pelo terror de viver, em menos de um segundo estilhaçava-me toda em pânico, e controlava como podia o meu mais profundo grito. Quase correndo de medo, cega entre as pessoas, terminei no outro quarteirão, encostada a um poste, cerrando violentamente os olhos, que não queriam mais ver. Mas a imagem colava-se às pálpebras: um grande rato ruivo, de cauda enorme, com os pés esmagados, e morto, quieto, ruivo. (LISPECTOR, 1998, p. 42)

Desde então, a caminhante se preocupa em entender o nexo entre o que sentira antes e o rato: "de que Deus estava querendo me lembrar?" (LISPECTOR, 1998 p. 42). 
O momento marca a passagem de lugares, sensações e narrativas no conto em questão. A "cidade maravilhosa", seus edifícios, as nesgas do mar dão lugar à paisagem do rato morto, como representação, entre outras coisas, das mazelas sociais. A paz do passeio é tomada pelo medo, seguido da indignação - no texto, enfatizada por meio de perguntas sequenciais.

Mas o rato morto anunciava também a angústia, o incômodo, as tensóes intrínsecas ao próprio sujeito. O desordenado, o desorganizado, o indomável. Se quer amar o mundo tem de amar também o seu inverso, o seu subterrâneo. É essa a condição do amor.

Porém, antes da constataçáo da complexidade que envolve o verbo amar - e viver -, a indignação desemboca no desejo de vingança. Vingança feita linguagem contra um Deus traidor:

Então a vingança dos fracos me ocorreu: ah, é assim? Pois então não guardarei segredo, e vou contar. Sei que é ignóbil ter entrado na intimidade de Alguém, e depois contar os segredos, mas vou contar - não conte, só por carinho não conte, guarde para você mesma as vergonhas Dele - mas vou contar sim, vou espalhar isso que me aconteceu, dessa vez não vai ficar por isso mesmo, vou contar o que Ele fez, vou estragar a Sua reputação. (LISPECTOR, 1998, p. 43).

O poder dado à palavra revela a força que Clarice atribuía à linguagem em sua própria vida. Para ela, a palavra agencia as emoçóes, age sobre a angústia inerente à existência, é alimento da vida.

$\mathrm{Na}$ entrevista outrora mencionada, três falas de CL reiteram sua relação visceral com a palavra:

Clarice Lispector (1977) - Tenho periodos de produzir intensamente e tenho periodos-hiatos em que a vida fica intolerável.

[Os hiatos] podem ser longos e eu vegeto nesse período ou então, para me salvar, me lanço logo noutra coisa.

Eu acho que, quando não escrevo estou morta.

A palavra como alimento da vida é também, na perspectiva psicanalítica, a ponte fundamental entre o "indivíduo" e o grande Outro: a arte, a cultura etc. (LACAN, 1999). É pela linguagem, de maneira geral, que o sujeito constrói suas representações de mundo.

Nesse exercício de se enxergar sujeito no/do mundo, a personagem descobre o seu narcisismo acentuado. A metáfora do rato é então deslocada ao plano da subjetividade. Essa é, aliás, uma chave de compreensão da obra de Clarice: há sempre um fato externo que dá passagem ao "verdadeiro enredo", aquele que se passa no labirinto psíquico do sujeito.

O rato torna-se o grande Outro: o desconhecido, o indomável, o incontrolável, o temido. E o problema, agora já interno ao sujeito, leva a personagem a reconhecer suas fragilidades, desenvolvendo a autocrítica. E, a perdoar Deus, à medida que toma para si a responsabilidade pelas próprias escolhas. 


\section{O JOGO DE CONTRADIÇÓES}

O Rio de Janeiro enquanto espaço da narrativa incita o leitor a pensar a cidade. Náo qualquer cidade: o "cartão postal do Brasil", especificamente Copacabana, região do mais caro metro quadrado do país.

Entendendo a especulação imobiliária em cidades turísticas como o Rio de Janeiro, como uma das estratégias de legitimação das disputas territoriais, cujo fundamento é a luta de classe (SANTOS, 2009), é possível conceber o rato morto como uma representação dos sujeitos e populaçóes expropriadas na produção do espaço urbano.

O "cartão postal do Brasil" é, nesse sentido, o cenário onde as contradiçôes sociais se fazem latentes. E, ainda que uma "limpeza" social e arquitetônica preceda a materializaçáo dos interesses dominantes na cidade, os efeitos retornam a esses espaços, sobretudo em matéria de violência.

"Perdoando Deus" ilustra o movimento dialético entre a produçáo do espaço e o processo de subjetivaçáo, sempre conflituosos. As emoçóes desencadeadas ao longo do passeio interferem na percepção do espaço, alterando também a estratégia discursiva empreendida: aos poucos, o texto descritivo cede ao texto reflexivo.

$\mathrm{Na}$ interação entre o espaço e a subjetividade, ocorrem, conforme Rolnik (2006), as "mutaçôes de sensibilidade", individuais e coletivas. Daí a passagem da contemplação à indignação, à vingança e à aceitação vivenciadas pela personagem conforme novos elementos espaciais se apresentavam.

Não há, portanto, como dissociar o sujeito problematizado no conto do espaço urbano - sobre o qual se desenvolve a narrativa, e da temporalidade favorecida por esse espaço.

A transposição das questóes colocadas por CL aos tempos atuais deve levar em consideraçáo as peculiaridades do tempo social presente, pois

[...] o sujeito de nossa formação social está, de certo modo, "amarrado" à individualidade. Ou seja, esta não é a simples expressão de sua liberdade, mas, até certo ponto, é uma injunçâa: injunçấo esta que, nos procedimentos pedagógicos, aparece como a compulsão à "originalidade" ou obsessão da "criatividade" obrigatória. Essa exigência mostra, na realidade, a necessidade que temos de um sujeito individualizado, visível, calculável, logo, identificável e, portanto, passível de controle. Um sujeito que se apresente com coerência, com certa permanência (duração), certa especificidade, e do qual se pode dizer algo, podendo-se, consequentemente, ter dele um certo domínio. (ORLANDI, 2006, pp. 105-106).

Destacam-se, portanto, duas concepçóes de liberdade: a liberdade enquanto argumento retórico e esteio de modos de subjetivação que fragmentam o tecido social, e a liberdade clariciana, sinônimo de consciência da natureza mutável e contraditória do desejo.

$\mathrm{Na}$ tentativa de sintetizar as consideraçôes conduzidas no texto, elaborou-se o seguinte organograma em forma de espiral: 
Figura 1: Espiral-analítico do conto "Perdoando Deus", de Clarice Lispector.

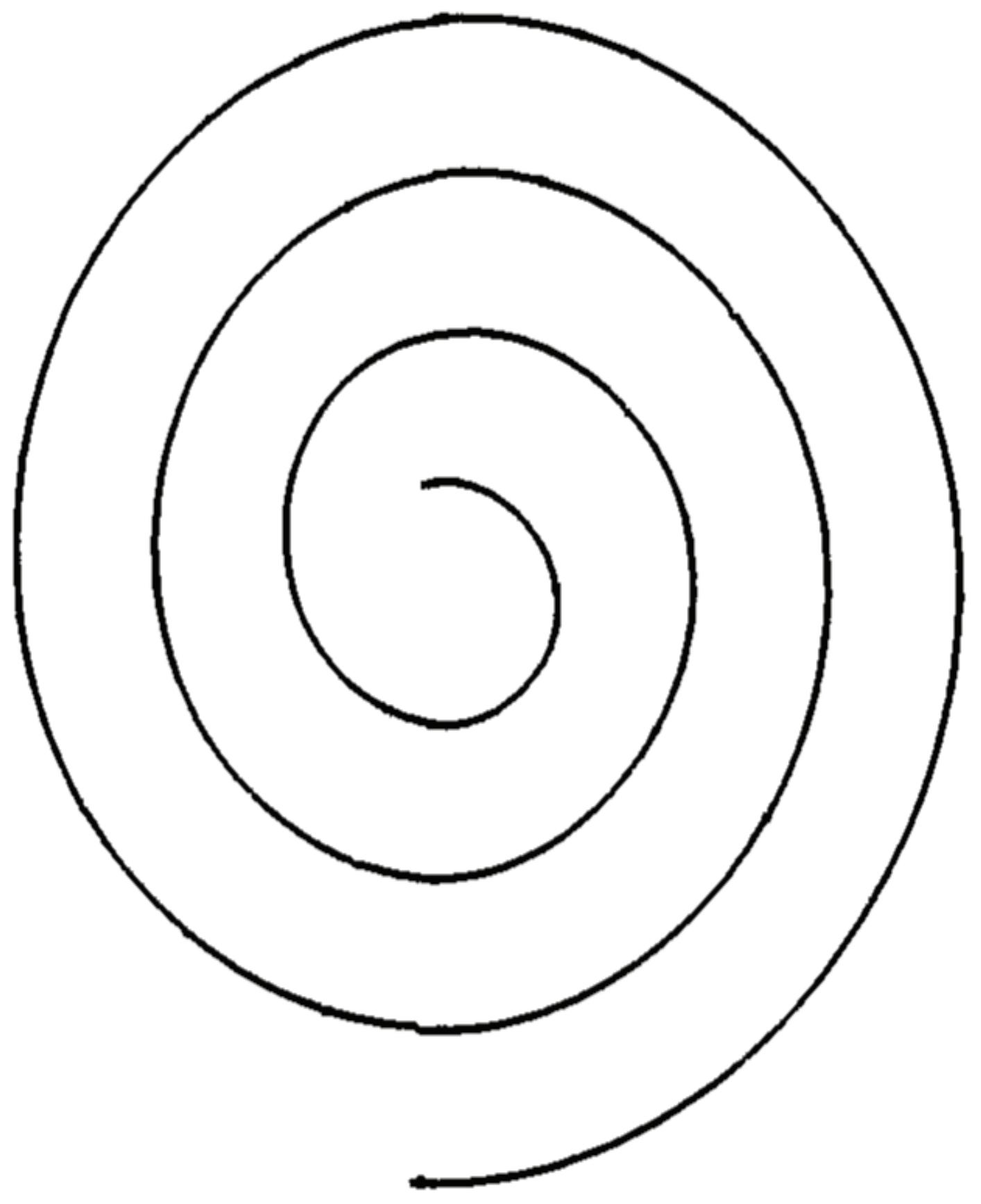

Elaboração: Marques, Ana C. O. 2016.

O espiral sugere a ideia de movimento e profundidade fundamentais à interpretação dos escritos de CL. A dubiedade do começo, e consequentemente do fim, é ainda consoante à natureza caótica do desejo, admitida pela escritora tanto na ficção quanto na realidade - se é que essas coisas podem ser isoladas quando o assunto é Clarice Lispector. 


\section{CONSIDERAÇÓES FINAIS}

As conexóes entre a escritora, a escrita e as possibilidades de leitura vislumbradas no conto "Perdoando Deus", de Clarice Lispector, apontaram, entre outras coisas, para o caráter visionário da literatura.

Datadas do século passado, as questóes colocadas por Clarice Lispector, dizem da realidade social contemporânea. Dizem das contradiçóes sociais, e dos modos de subjetivação, hoje fatores de um mal-estar social generalizado nas grandes cidades.

Entretanto, como advertido na introdução do artigo, a aproximação com a literatura - ou qualquer outra expressão artística - perde sua vitalidade quando esta, a literatura, é vista pela ótica da "aplicabilidade", da utilidade.

A força da literatura enquanto INSCRIÇÃO de dizeres, fazeres, "sentires" que ampliam a marginalidade social e acadêmica, e por isso fogem à lógica institucional, está na potencialidade criativa. E a criaçáo esvai-se quando "capturada" pela lógica utilitarista. Isso não torna a literatura esvaziada de sentido ou papel na transformação social. Apenas lhe garante como premissa a abertura às complexas teias de sentidos que os sujeitos constroem nessa conflituosa relaçáo com o mundo. A finalidade supóe um fim, e a literatura alimenta-se da possibilidade. Possibilidade de composição de novas palavras, novas narrativas, novos enredos, novas sensibilidades, novas formas de existir.

O conteúdo existencialista do conto "Perdoando Deus" tira o sujeito da passividade e da impessoalidade na produçáo da existência na grande cidade. Confronta-o com aquilo que é mais belo e mais horrendo da vida urbana. Convoca o sujeito a realizar escolhas, reflexóes, a problematizar o próprio desejo. Dessa forma, lança luz aos modos com que os temas do mundo - violência, segregaçáo espacial, desigualdade social - atingem a subjetividade.

Nessa relação sujeito-mundo, sensações das mais diversas alternam-se, sobrepõem-se, conforme os espaços percebidos e vividos. A percepçáo do espaço é, portanto, elementochave na produção do desejo. E, esse desejo, não estanque, age no espaço concreto.

Ao ler Clarice, o sujeito-leitor é provocado a problematizar sua relaçáo com o mundo, enquanto mundo-fábrica de desejos. 


\section{REFERÊNCIAS BIBLIOGRÁFICAS}

CHARTIER, Roger. A história cultural - entre práticas e representações. Rio de Janeiro: Editora Bertrand Brasil S.A, 1990

CHAVEIRO, Eguimar. Leitura e engajamento: um tributo a Eduardo Galeano, de Luiz Carlos Fadel. Inédito.

CRUVINEL, Gilberto. A bruxaria literária de Clarice Lispector. Folha de Sáo Paulo, 02/08/2015. Disponível em: http://www1.folha.uol.com.br/ilustrissima/2015/08/16628 54-a-bruxaria-literaria-de-clarice-lispector.shtml. Acesso em: abr. 2015.

LACAN, Jaques. O seminário, livro 5: as formaçóes do inconsciente. Rio de Janeiro: Jorge Zahar Ed., 1999.

LISPECTOR, Clarice. Entrevista concedia à Júlio Lerner, TV Cultura. 1977. Disponível em:http://jornalggn.com.br/blog/luisnassif/a-ultima-entrevista-de-clarice-lispector. Acesso em: abr. 2016.

LISPECTOR, Clarice. Felicidade Clandestina. Rio de Janeiro: Rocco, 1998.

MANGUEL, Alberto. Uma história da leitura. /Alberto Manguel; tradução Pedro Maia Soares. - São Paulo: Companhia das Letras, 1997.

MOREIRA, Ruy. Pensar e ser em geografia: ensaios de história, epistemologia e ontologia do espaço geográfico. Editora Contexto, 2011.

ORLANDI, Eni P. Discurso e leitura. - 7. ed. - São Paulo: Cortez, 2006.

ROLNIK, Suely. Cartografia sentimental: transformaçóes contemporâneas do desejo. 2. ed., Porto Alegre: Sulina; Editora da UFRGS, 2014. 247 p.

SANTOS, Milton. A Natureza do Espaço: Técnica e Tempo, Razão e Emoção. 4. ed., 5. reimpr. - São Paulo: Editora da Universidade de São Paulo, 2009. - (Coleção Milton Santos; 1).

Recebido em junho de 2017. Aprovado em dezembro de 2017. 